\title{
RESEARCH
}

Open Access

\section{Recapitulation of methotrexate hepatotoxicity with induced pluripotent stem cell-derived hepatocytes from patients with rheumatoid arthritis}

Juryun Kim ${ }^{1,2,3}$, Yena Kim ${ }^{1,2,3}$, Jinhyeok Choi ${ }^{1,2,3}$, Hyerin Jung ${ }^{1,2,3}$, Kijun Lee ${ }^{1,2,3}$, Jaewoo Kang ${ }^{1,2,3}$, Narae Park ${ }^{1,2,3}$, Yeri Alice Rim ${ }^{1,2,3}$, Yoojun $\mathrm{Nam}^{1,2,3}$ and Ji Hyeon Ju, ${ }^{1,2^{*}}$

\begin{abstract}
Background: Methotrexate (MTX) is widely used for the treatment of rheumatoid arthritis (RA). The drug is cost-effective, but sometimes causes hepatotoxicity, requiring a physician's attention. In this study, we simulated hepatotoxicity by treating hepatocytes derived from RA patient-derived induced pluripotent stem cells (RA-iPSCs) with MTX.

Methods: RA-iPSCs and healthy control iPSCs (HC-iPSCs) were established successfully. RA-iPSCs were differentiated into hepatocytes in two-dimensional (2D) monolayers and three-dimensional (3D) hepatocyte spheroid cultures; this process required growth factors such as BMP4, bFGF, HGF, and OSM. Immunofluorescence staining and flow cytometry were performed to confirm that the mature hepatocytes expressed cytokeratin 18, anti-alpha-1 antitrypsin, and albumin. MTX toxicity was evaluated via monitoring of cell viability, alanine aminotransferase, and mitochondrial status after MTX treatment in 2D and 3D cultures.

Results: RA-iPSCs generated from three RA patients suffering from MTX-induced hepatotoxicity differentiated into the endoderm lineage, hepatoblasts, and hepatocytes. In 2D culture, RA-iPSC-derived hepatocytes were more sensitive to MTX than healthy controls. A 3D culture system using hepatocyte spheroids also successfully recapitulated MTX-induced hepatotoxicity. The 3D culture system had several advantages, including longer culture periods under more complex conditions.
\end{abstract}

Conclusions: A patient-derived iPSC platform could recapitulate MTX toxicity. Simulation of drug toxicity in vitro may help clinicians choose safer drugs or less toxic doses.

Keywords: Induced pluripotent stem cells, Hepatocyte, Hepatocyte spheroid, Methotrexate, Drug-induced hepatotoxicity, Rheumatoid arthritis

\footnotetext{
* Correspondence: juji@catholic.ac.kr

${ }^{1}$ CiSTEM laboratory, Convergent Research Consortium for Immunologic

Disease, Seoul St. Mary's Hospital, College of Medicine, The Catholic

University of Korea, Seoul 137-701, Republic of Korea

2Division of Rheumatology, Department of Internal Medicine, Seoul St. Mary's

Hospital, Institute of Medical Science, College of Medicine, The Catholic

University of Korea, \#505, Banpo-Dong, Seocho-Gu, Seoul 137-701, Republic

of Korea

Full list of author information is available at the end of the article
}

(c) The Author(s). 2018 Open Access This article is distributed under the terms of the Creative Commons Attribution 4.0 International License (http://creativecommons.org/licenses/by/4.0/), which permits unrestricted use, distribution, and reproduction in any medium, provided you give appropriate credit to the original author(s) and the source, provide a link to the Creative Commons license, and indicate if changes were made. The Creative Commons Public Domain Dedication waiver (http://creativecommons.org/publicdomain/zero/1.0/) applies to the data made available in this article, unless otherwise stated. 


\section{Background}

Rheumatoid arthritis (RA) is a chronic disease that causes inflammation and destruction of bone and is associated with signs of systemic immune imbalance. To treat RA, drugs such as nonsteroidal anti-inflammatory drugs (NSAIDs), disease-modifying antirheumatic drugs (DMARDs), and biological reagents are prescribed according to the severity of pathology [1, 2]. Among these medications, methotrexate (MTX) is the gold standard for treatment of RA and is commonly prescribed to patients.

MTX, a folic acid antagonist derived from aminopterin, inhibits the enzyme dihydrofolate reductase and has anti-inflammatory activity [3]. However, a subset of RA patients taking this medicine for long periods exhibit drug-induced liver injury, resulting in abnormally elevated levels of aspartate aminotransferase (AST) and alanine aminotransferase (ALT). Consequently, even though MTX is cost-effective, physicians must restrict prescription of this drug due to its hepatotoxicity $[4,5]$.

Primary hepatocytes derived from patient liver tissue have been used to predict and measure hepatotoxicity. However, because primary hepatocytes cannot proliferate and have a short lifespan in culture, they are of limited utility for toxicology. For many years, immortal liver cancer cell lines such as HepG2 and HepaRG have been used to estimate hepatotoxicity, but their sensitivity is low, and these cell lines fail to reflect the patient's characteristics [6, 7].

Human-induced pluripotent stem cells (iPSCs), which are induced by viruses expressing the Yamanaka factors (OCT4, Sox2, Klf4, c-Myc), can be generated from multiple types of somatic cells, including fibroblasts and peripheral blood mononuclear cells (PBMCs) [8]. Their ability to differentiate into all three germ layers enables iPSCs to produce hepatocyte-like cells, via the endodermal state, under the influence of diverse growth factors. Hepatocytes induced from iPSCs have liver function comparable to that of immortal cell lines, express albumin, and the enzyme A1AT and are suitable for use as in vitro disease models [9-12]. Moreover, the self-renewal properties of iPSCs overcome the limitations on primary hepatocyte proliferation. To date, however, no study has sought to verify hepatotoxicity in hepatocyte-like cells using iPSCs derived from RA patients' somatic cells.

In recent work, iPSCs have been used to study hepatotoxicity [13-15]. In several studies, iPSCs were differentiated into endoderm, hepatoblasts, immature hepatocytes, and mature hepatocytes using growth factors such as Activin A, basic fibroblast growth factor (bFGF), bone morphogenetic protein 4 (BMP4), hepatocyte growth factor (HGF), and Oncostatin M (OSM) [16-19]. In addition, hepatocyte-like cells have been derived from iPSCs using small molecules such as CHIR99021 [20], and recent studies have used small molecules such as FH1 to promote maturation of differentiated hepatocyte-like cells [21]. All of these studies were conducted using two-dimensional (2D) monolayer culture and have overcome the problem of providing a cell source, which as noted above is an issue when using primary hepatocytes. However, the induced cells live only 6-10 days after the completion of differentiation, making it difficult to measure long-term toxicity or drug efficacy over long periods of time. To overcome this problem, a three-dimensional (3D) culture system similar to the in vivo environment has been developed with the goal of increasing the lifespan of primary hepatocytes (or iPSC-derived hepatocytes), as well as boosting albumin secretion and other hepatocyte functions [22, 23].

In this study, we sought to investigate the toxicity of MTX over the short term in 2D monolayer culture and furthermore to determine the toxicity of MTX over the long term by differentiating iPSC-derived hepatocytes in spheroid culture. To this end, we generated iPSCs from somatic cells of RA patients with MTX-induced hepatotoxicity or healthy controls, and then differentiated these iPSCs into hepatocyte-like cells and 3D hepatocyte spheroids using growth factors. Using the resultant hepatocyte-like cells and spheroids, we attempted to simulate MTX hepatotoxicity.

\section{Methods}

\section{Differentiation of iPSCs}

To generate iPSCs, PBMCs and skin cells were obtained from RA patients with hepatotoxicity caused by MTX treatment, as well as from healthy control subjects. iPSCs were generated as previously described [24]. Briefly, PBMCs obtained from each group were cultured for 4 days in StemSpan medium (STEMCELL Technologies, Vancouver, Canada) to expand CD34-positive cells. Expanded PBMCs or skin cells were transfected with the CytoTune-iPS Sendai Reprogramming Kit (Life Technologies, Carlsbad, CA, USA) including the Yamanaka factors (Oct4, Sox2, KLF4, and c-Myc). PBMCs were induced to form iPSCs by centrifugation; the resultant attached cells were expanded and purified by colony picking.

\section{Blood samples, skin samples, and ethics statement}

The Institutional Review Board (IRB) of the Catholic University of Korea, Seoul St. Mary's Hospital, approved this study (IRB Number: KC13TISI0775).

\section{Differentiation of hepatocyte-like cells}

Human iPSCs were subcultured in dishes coated with vitronectin at $37^{\circ} \mathrm{C}$ in an incubator containing $10 \% \mathrm{CO}_{2}$. Fresh Essential 8 (E8) medium, replaced once per day, was used as the culture medium. iPSCs were split using 
trypsin-EDTA (TE) at 70\% confluence, and $10 \mu \mathrm{M}$ rho-associated kinase (ROCK) inhibitor was added to the newly passaged cells. To differentiate into endoderm, STEMdiff definitive endoderm basal medium (STEMCELL Technologies) was used as the culture medium. Briefly, on day 1, STEMdiff definitive endoderm basal medium containing supplements $\mathrm{A}$ and $\mathrm{B}$ was added to the plate containing packed iPSCs. On days $2-4$, the medium was replaced with medium prepared by diluting STEMdiff definitive endoderm basal medium with only supplement B. On days 5-7, the plate was washed with RPMI 1640 medium, and the medium was replaced with RPMI/B27 medium supplemented with $10 \mathrm{ng} / \mathrm{mL}$ bFGF and $20 \mathrm{ng} / \mathrm{mL}$ BMP4. On day 8 , the medium was replaced with hepatocyte basal medium (HBM) (Lonza, Basel, Switzerland) containing $50 \mathrm{ng} / \mathrm{mL}$ HGF (Peprotech, NJ, USA) and $30 \mathrm{ng} / \mathrm{mL}$ OSM (R\&D Systems, Minneapolis, MN, USA). To re-plate hepatoblasts into proper microplates, the cells were dissociated with TE and seeded into 96-well plates or the indicated culture vessel. For passage, hepatoblast medium was removed from culture plates, the plates were washed with sterile phosphate-buffered saline (PBS), and the cells were dissociated with TE. Hepatoblasts were collected with hepatoblast basal medium and pelleted by centrifugation (1100 rpm, $27^{\circ} \mathrm{C}, 2 \mathrm{~min}$ ). For 96 -well plates, $3.3 \times 10^{4}$ hepatoblasts were seeded in growth-factor-reduced Matrigel (BD Biosciences, San Jose, CA, USA)-coated wells in hepatocyte medium supplemented with $50 \mathrm{ng} /$ $\mathrm{mL}$ HGF (Peprotech), $30 \mathrm{ng} / \mathrm{mL}$ OSM (R\&D), and ROCK inhibitor. From day 10 until day 26, new hepatocyte medium was replaced with $50 \mathrm{ng} / \mathrm{mL}$ HGF and 30 $\mathrm{ng} / \mathrm{mL}$ OSM every other day.

\section{D hepatocyte spheroid differentiation}

A 96-well round-bottomed plate was coated for $5 \mathrm{~min}$ with anti-adherent rinsing solution (STEMCELL Technologies) and washed once with PBS. To prepare culture medium for generation of spheroids, HBM was supplemented with $50 \mathrm{ng} / \mathrm{mL}$ HGF, $30 \mathrm{ng} / \mathrm{mL}$ OSM, and 1:100 $(v / v)$ BD Matrigel ${ }^{\mathrm{mm}}$ Basement Membrane Matrix (BD Biosciences, San Jose, CA, USA). On day 8 of differentiation, hepatoblasts differentiated from iPSCs were dissociated with TE. Five thousand hepatoblast cells in $100 \mu \mathrm{L}$ of medium, prepared as described above, were seeded in each well of the pre-coated 96-well round-bottomed plate, which was then centrifuged at $300 \mathrm{~g}$ for $3 \mathrm{~min}$. Subsequently, the medium was replaced every other day with HBM containing $50 \mathrm{ng} / \mathrm{mL}$ HGF and $30 \mathrm{ng} / \mathrm{mL}$ OSM.

\section{Real-time PCR}

RNA was extracted from iPSCs using TRIzol (Life Technologies), and cDNA was synthesized using RevertAid ${ }^{\mathrm{mm}}$ First Strand cDNA Synthesis Kit (Thermo Fisher
Scientific, Waltham, MA, USA). Real-time PCR was performed using SYBR Green real-time PCR master mix (Roche, Basel, Switzerland) and RT PCR was performed using i-Taq ${ }^{\text {Tw }}$ DNA Polymerase (iNtRON BIOTECHNOLOGY, Seongnam, South Korea). Primer sequences are shown in Table 1.

\section{Quantitative analysis of gene expression for drug metabolism}

RNA was extracted from HepG2 cells and iPSCs using TRIzol when cells were 60 70\% confluent after seeding. In the case of iPSC-derived hepatocyte, RNA was extracted using TRIzol after completion of differentiation. cDNA was synthesized and real-time PCR was performed using primers of phases I, II, and III and nuclear receptor. Real-time PCR was conducted using a LightCycler $^{\circ} 480$ Instrument II (Roche, Basel, Switzerland). Mean cycle threshold values of target gene expression was normalized with the value of the housekeeping gene, glyceraldehyde 3-phosphate dehydrogenase (GAPDH). All experiments were performed in triplicate. Primer sequences are shown in Table 1.

\section{Immunofluorescence staining}

On day 8 , hepatoblasts were seeded into 12-well plates containing cover glasses pre-coated with Matrigel. Cells were differentiated into hepatocyte-like cells as described in the differentiation protocol above. After two washes with $500 \mu \mathrm{L}$ of PBS, the cells were incubated with $4 \%$ paraformaldehyde for $30 \mathrm{~min}$, washed two more times with PBS, incubated with $50 \mathrm{mM} \mathrm{NH}_{4} \mathrm{Cl}$ solution for $10 \mathrm{~min}$, washed again twice with PBS, incubated with $500 \mu \mathrm{L}$ of $0.1 \%$ Triton $\mathrm{X}-100$ for $10 \mathrm{~min}$, incubated with $500 \mu \mathrm{L}$ of $2 \%$ PBA for 30 $\mathrm{min}$, incubated at room temperature for $2 \mathrm{~h}$ with primary antibodies diluted in fresh 2\% PBA blocking buffer (anti-albumin, 1:200; anti-A1AT, 1:200; anti-AFP, 1:1000; anti-CK18, 1:500; anti-CYP3A4, 1:100), washed two times with $500 \mu \mathrm{L}$ of $2 \%$ PBA, and then incubated for $1 \mathrm{~h}$ at room temperature with fluorescence-conjugated secondary antibody diluted in 2\% PBA buffer. After washing, the cells were mounted using antifade and visualized on a fluorescence microscope.

\section{Periodic acid-Schiff staining}

On day 8 , hepatoblasts were seeded in 12-well plates pre-coated with Matrigel. Cells were cultured until day 26 in HBM as described in the differentiation protocol above. After two washes with $500 \mu \mathrm{L}$ of PBS, the cells were incubated with $4 \%$ paraformaldehyde for $30 \mathrm{~min}$, washed with PBS, incubated for $10 \mathrm{~min}$ with $0.1 \%$ Triton $\mathrm{X}-100$, acidified for $5 \mathrm{~min}$ with $1 \%$ periodic acid (Sigma-Aldrich, St. Louis, MO, USA), washed three times with distilled water, and treated with Schiff's reagent for 20 min. After Schiff's reagent was aspirated, the cells 
Table 1 Sequences of primers used for PCR

\begin{tabular}{|c|c|c|c|}
\hline Target name & Direction & Primer sequence $\left(5^{\prime}-3^{\prime}\right)$ & Size (bp) \\
\hline \multirow[t]{2}{*}{ ОСТ3/4 } & Forward & ACCCCTGGTGCCGTGAA & 190 \\
\hline & Reverse & GGCTGAATACCTTCCCAAATA & \\
\hline \multirow[t]{2}{*}{ SOX2 } & Forward & CAGCGCATGGACAGTTAC & 321 \\
\hline & Reverse & GGAGTGGGAGGAAGAGGT & \\
\hline \multirow[t]{2}{*}{ NANOG } & Forward & AAAGGCAAACAACCCACT & 270 \\
\hline & Reverse & GCTATTCTTCGGCCAGTT & \\
\hline \multirow[t]{2}{*}{ DPPA5 } & Forward & CGGCTGCTGAAAGCCATTIT & 215 \\
\hline & Reverse & AGTTTGAGCATCCCTCGCTC & \\
\hline \multirow[t]{2}{*}{ LIN28 } & Forward & GTTCGGCTTCCTGTCCAT & 122 \\
\hline & Reverse & CTGCCTCACCCTCCTTCA & \\
\hline \multirow[t]{2}{*}{ ALB } & Forward & TTGGCACAATGAAGTGGGTA & 161 \\
\hline & Reverse & AAAGGCAATCAACACCAAGG & \\
\hline \multirow[t]{2}{*}{ CYP1A2 } & Forward & ATGGCATTGTCCCAGTCTGTT & 135 \\
\hline & Reverse & TGGCTCTGGTGGACTITCAG & \\
\hline \multirow[t]{2}{*}{ CYP2D6 } & Forward & GTGTCCAACAGGAGATCGACG & 101 \\
\hline & Reverse & CACCTCATGAATCACGGCAGT & \\
\hline \multirow[t]{2}{*}{ CYP2E1 } & Forward & GTTCTTTGGGGGACAGAGA & 202 \\
\hline & Reverse & GAGGGTGATGAACCGCTGAA & \\
\hline \multirow[t]{2}{*}{ CYP3A4 } & Forward & TGTGCCTGAGAACACCAGAG & 226 \\
\hline & Reverse & GTGGTGGAAATAGTCCCGTG & \\
\hline \multirow[t]{2}{*}{ CYP3A7 } & Forward & GAAACACAGATCCCCCTGAA & 105 \\
\hline & Reverse & TCAGGCTCCACTTACGGTCT & \\
\hline \multirow[t]{2}{*}{ UGT1A1 } & Forward & CAGCAGAGGGGACATGAAAT & 174 \\
\hline & Reverse & ACGCTGCAGGAAAGAATCAT & \\
\hline \multirow[t]{2}{*}{ UGT2B15 } & Forward & GTGTTGGGAATATTATGACTACAGTAAC & 157 \\
\hline & Reverse & GGGTATGTTAAATAGTTCAGCCAGT & \\
\hline \multirow[t]{2}{*}{ OATP1B1 } & Forward & GAGCAACAGTATGGTCAGCCT & 135 \\
\hline & Reverse & GGCAATTCCAACGGTGTTCA & \\
\hline \multirow[t]{2}{*}{ OATP1B3 } & Forward & GTCCAGTCATTGGCTITGCA & 111 \\
\hline & Reverse & CAACCCAACGAGAGTCCTTAGG & \\
\hline \multirow[t]{2}{*}{ NTCP } & Forward & GGGACATGAACCTCAGCATT & 199 \\
\hline & Reverse & CGTTTGGATTTGAGGACGAT & \\
\hline \multirow[t]{2}{*}{ MRP2 } & Forward & AGCGTCCTCTGACACTCG & 206 \\
\hline & Reverse & GGCATCTTGGCTITGACT & \\
\hline \multirow[t]{2}{*}{ MDR1 } & Forward & CTAATGCCGAACACATTGGA & 237 \\
\hline & Reverse & CAGTCGCTTTATTTCTTTGCC & \\
\hline \multirow[t]{2}{*}{ AHR } & Forward & CAAATCCTTCCAAGCGGCATA & 123 \\
\hline & Reverse & CGCTGAGCCTAAGAACTGAAAG & \\
\hline \multirow[t]{2}{*}{ FXR } & Forward & CAGGATTTCAGACTTTGGACCAT & 63 \\
\hline & Reverse & CTTCAACCGCAGACCCTTTC & \\
\hline \multirow[t]{2}{*}{ GR } & Forward & ATAGCTCTGTTCCAGACTCAACT & 111 \\
\hline & Reverse & TCCTGAAACCTGGTATTGCCT & \\
\hline \multirow[t]{2}{*}{ PPARa } & Forward & AGAGATTTCGCAATCCATCGG & 62 \\
\hline & Reverse & ACTGGTATTCCGTAAAGCCAAAG & \\
\hline
\end{tabular}


Table 1 Sequences of primers used for PCR (Continued)

\begin{tabular}{|c|c|c|c|}
\hline Target name & Direction & Primer sequence $\left(5^{\prime}-3^{\prime}\right)$ & Size (bp) \\
\hline \multirow[t]{2}{*}{ RXRA } & Forward & ATGGACACCAAACATTTCCTGC & 211 \\
\hline & Reverse & GGGAGCTGATGACCGAGAAAG & \\
\hline \multirow[t]{2}{*}{ SHP } & Forward & CCCCAAGGAATATGCCTGCC & 233 \\
\hline & Reverse & TAGGGCGAAAGAAGAGGTCCC & \\
\hline \multirow[t]{2}{*}{ ADORA1 } & Forward & GTCCTCATCCTCACCCAGAG & 189 \\
\hline & Reverse & CAGATTGTTCCAGCCAAACA & \\
\hline \multirow[t]{2}{*}{ ADORA2A } & Forward & CGAGGGCTAAGGGCATCATTG & 98 \\
\hline & Reverse & CTCCTTTGGCTGACCGCAGTT & \\
\hline \multirow[t]{2}{*}{ ADORA2B } & Forward & СTCTTCCTCGCCTGCTTCGTG & 107 \\
\hline & Reverse & TTATACCTGAGCGGGACACAG & \\
\hline \multirow[t]{2}{*}{ ADORA3 } & Forward & TACATCATTCGGAACAAACTC & 80 \\
\hline & Reverse & GTCTTGAACTCCCGTCCATAA & \\
\hline \multirow[t]{2}{*}{ CD39 } & Forward & ACAGGCGTGGTGCATCAAGTAGAA & 279 \\
\hline & Reverse & CCTGGCACCCTGGAAGTCAAAG & \\
\hline \multirow[t]{2}{*}{ CD73 } & Forward & CAGTACCAGGGCACTATCTG & 194 \\
\hline & Reverse & AGTGGCCCCTTTGCTTTAAT & \\
\hline \multirow[t]{2}{*}{ GAPDH } & Forward & GAATGGGCAGCCGTTAGGAA & 414 \\
\hline & Reverse & GACTCCACGACGTACTCAGC & \\
\hline
\end{tabular}

were washed in distilled water for $5 \mathrm{~min}$. After replacement of the wash solution with fresh distilled water, staining was visualized under a light microscope.

\section{CCK-8 assay}

Human iPSCs were induced to form hepatocytes as described above. On day 8 , the cells were re-seeded into 96-well microplates $\left(3.3 \times 10^{4}\right.$ cells/well). On day 21 of hepatocyte differentiation, MTX was administered at a dose of $0 \mathrm{nM}, 1 \mathrm{nM}, 10 \mathrm{nM}, 100 \mathrm{nM}, 1 \mu \mathrm{M}, 10 \mu \mathrm{M}$, or $100 \mu \mathrm{M}$, and the cells were cultured for 6 days with a medium change every other day. The cells were then treated with $10 \mu \mathrm{L}$ of CCK- 8 solution per well and incubated for $30 \mathrm{~min} \sim 4 \mathrm{~h}$ at $37^{\circ} \mathrm{C}$ in an incubator, and absorbance was measured at $450 \mathrm{~nm}$.

\section{Flow cytometry}

Hepatocyte-like cells derived from iPSCs were dissociated using Accumax (Innovative Cell Technologies, San Diego, CA, USA). Cells were washed twice with PBS containing 2\% FBS, permeabilized for 30 min using Flow Cytometry Fixation and Permeabilization Buffer (Thermo Fisher Scientific, MA, USA), washed with wash buffer, stained with allophycocyanin (APC)-conjugated human albumin antibody (R\&D Systems) and Oct4 antibody (Abcam, Cambridge, UK) for $1 \mathrm{~h}$ each, and then washed with wash buffer. Analysis was performed on a BD LSRFortessa cell analyzer (BD Biosciences), and data were analyzed using the FlowJo V10 Single Cell Analysis Software (TreeStar Inc., OR, USA).

\section{ALT activity assay}

Starting on day 21 of hepatocyte differentiation, MTX was administered at a dose of $0 \mathrm{nM}, 1 \mathrm{nM}, 10$ $\mathrm{nM}, 100 \mathrm{nM}, 1 \mu \mathrm{M}, 10 \mu \mathrm{M}$, or $100 \mu \mathrm{M}$ once every 2 days for 6 days. Culture supernatants were collected, and ALT activity was detected manually using the Alanine Aminotransferase activity assay (Sigma-Aldrich). Briefly, culture supernatant in each well of a 96-well plate was mixed with a master reaction mix containing ALT assay buffer, fluorescent peroxidase substrate, ALT enzyme mix, and sub-substrate. Initial fluorescence intensity $\left(\lambda_{\mathrm{ex}}=535 ; \lambda_{\mathrm{em}}=587 \mathrm{~nm}\right)$ was measured, and the sample was incubated at $37^{\circ} \mathrm{C}$ in the dark and assayed every $5 \mathrm{~min}$ until the measured value of the most active sample was greater than the highest standard value.

\section{D spheroid cell viability assay (ATP assay)}

Starting on day 21 of hepatocyte differentiation, MTX was administered at a dose of $0 \mathrm{nM}, 1 \mathrm{nM}, 10 \mathrm{nM}, 100$ $\mathrm{nM}, 1 \mu \mathrm{M}, 10 \mu \mathrm{M}$, or $100 \mu \mathrm{M}$ once every 2 days for 14 days. The CellTiter-Glo 3D cell viability assay reagent (Promega, Madison, WI, USA) was dissolved the day before and left at room temperature for $30 \mathrm{~min}$ before use. Spheroids in $100 \mu \mathrm{L}$ of culture medium were added to $100 \mu \mathrm{L}$ of the CellTiter-Glo 3D cell viability assay reagent and mixed vigorously for $30 \mathrm{~min}$ to lyse the cells. Absorbance was measured using a Luminometer (Spectra Max L, USA). 


\section{Live/dead cell staining}

Starting on day 21 of hepatocyte differentiation, MTX was administered at a dose of $0 \mathrm{nM}, 1 \mathrm{nM}, 10 \mathrm{nM}, 100$ $\mathrm{nM}, 1 \mu \mathrm{M}, 10 \mu \mathrm{M}$, or $100 \mu \mathrm{M}$ once every 2 days for 14 days. Ethidium homodimer and Calcein AM from the Live/DEAD Viability/Cytotoxicity Kit (Thermo Fisher Scientific) were slowly dissolved at room temperature. Ethidium homodimer was diluted 1:500 in PBS, and Calcein AM was diluted 1:2000; $200 \mu \mathrm{L}$ of both solutions was added to hepatocyte spheroids. After incubation at $37^{\circ} \mathrm{C}$ for $30 \mathrm{~min}$, the cells were washed with PBS, and a z-stack fluorescence image was obtained using a confocal microscope.

\section{Mitochondrial staining}

Starting on day 21 of hepatocyte differentiation, MTX was administered every other day for 14 days. After washing once with PBS, $10 \mu \mathrm{M}$ Mitotracker Orange CM-H2TMROS (Thermo Fisher Scientific) and $200 \mathrm{nM}$ Hoechst 33342 (Thermo Fisher Scientific) were added to the samples. After incubation for $30 \mathrm{~min}$, a z-stack fluorescence image was obtained on a confocal microscope.

\section{Statistical analysis}

The GraphPad Prism software (v. 5.01; GraphPad, San Diego, CA, USA) was used for statistical analysis. Statistical significance was assessed by Student's $t$ test and is expressed as follows: ", $p<0.05$; ***,$p<0.01$; ***, $p<0.001$.

\section{Results}

Generation of human iPSCs from a RA patient with MTXinduced hepatotoxicity

Somatic cells, such as skin fibroblasts or PBMCs, from healthy control subjects $(n=3)$ and RA patients with MTX-induced hepatotoxicity $(n=3)$ were induced to form iPSCs with Sendai virus expressing the Yamanaka factors (Oct4, Sox2, KLF4, c-Myc). The reprogramming method was based on a previous protocol using serial centrifugation [24]. Colonies were generated from somatic cells in about 18 days (Fig. 1a, b). RA patients had AST levels of $63-170 \mathrm{IU} / \mathrm{L}$ and ALT levels of 122-220 IU/L within 1 week after MTX administration (Table 2).

PCR analysis of gene expression revealed that the iPSCs expressed GAPDH, OCT3/4, NANOG, SOX2, $T D G F$, and DPPA5 (Fig. 1c, d). Flow cytometry revealed that about $90 \%$ in iPSCs were positive for pluripotency marker, OCT3/4 (Fig. 1e). In addition, we confirmed the expression of pluripotency markers OCT3/4, SSEA4, TRA-1-60, SOX2, TRA-1-81, and KLF4 at the protein level by immunofluorescence (Fig. 1f, Additional file 1a, b). To determine whether the generated iPSCs were pluripotent, we subjected them to alkaline phosphatase (AP) staining. iPSCs from three healthy controls and three RA patients with hepatotoxicity stained positively for AP, indicating that they were all pluripotent and had not yet differentiated into any of the germ layers (Additional file 1c, d).

\section{Differentiation of hepatocytes from iPSCs in 2D monolayer culture}

We prepared iPSC-derived hepatocyte-like cells resembling primary hepatocytes, which are difficult to cultivate in vitro, and attempted to use these cells to simulate the hepatotoxicity resulting from MTX administration in RA patients. Human iPSCs can be differentiated into three lineages (endoderm, mesoderm, ectoderm); in particular, iPSCs can be directly differentiated into endoderm and then into hepatocytes. We used a modified protocol employing growth factors [25] in which the cells progressed from endoderm to hepatoblast to hepatocyte-like cells; all cells had differentiated after 26 days (Fig. 2a). Differentiation into the endoderm and hepatoblast states was confirmed by expression of SOX17, an endoderm marker, and $\mathrm{HNF} 4 \alpha$, a hepatoblast marker, as determined by immunofluorescence (Additional file 2). Hepatocyte-like cells differentiated from iPSCs exhibited cell morphology similar to that of primary hepatocytes (Fig. 2b) [26]. Flow cytometry revealed that more than $80 \%$ of hepatocyte-like cells from both healthy controls and RA patients were positive for albumin, a hepatocyte marker (Fig. 2c). Moreover, periodic acid-Schiff (PAS) staining, which indicates glycogen storage function, was positive in cells derived from both healthy controls and RA patients and there was no significant difference between $\mathrm{HC}$ and RA groups (Fig. 2d). Expression of the hepatocyte marker CK18 (Fig. 2e) and A1AT marker (Fig. 2f) was confirmed by immunofluorescence assay (IFA), indicating that iPSCs were well differentiated into hepatocyte-like cells in both groups. In the case of AFP, a marker of immature hepatocytes, expression was significantly lower in controls than in the RA samples, indicating that iPSC-derived hepatocyte-like cells from RA patients had a higher proportion of immature hepatocytes (Fig. 2g). In the case of CYP3A4, another marker of mature hepatocytes, expression was significantly higher in controls than in the RA samples, indicating that iPSC-derived hepatocyte-like cells from RA patients had a lower proportion of mature hepatocytes (Fig. 2h). And gene expression for drug metabolism phases I, II, and III and nuclear receptors [27] was examined in iPSC-derived hepatocyte-like cells, iPSC (negative control) and HepG2 (positive control). First, OCT4, a pluripotency marker expressed in iPSC, was significantly reduced in iPSC-derived hepatocyte-like cells (Fig. 2i), and albumin expressed in hepatocytes was increased in hepatocyte-like cells compared to iPSCs (Fig. 2j). In the case of CYP3A4, CYP3A7, and CYP2E1 among Cytochrome $\mathrm{P} 450$ genes related to detoxicification of drug, HC iPSC and RA iPSC, which 


\section{a}

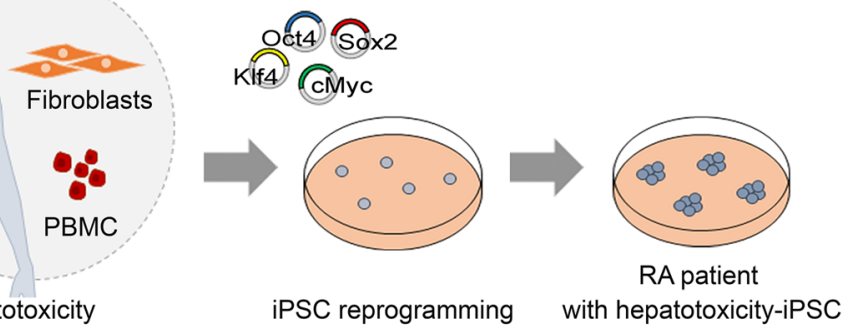

RA patients with hepatotoxicity

b

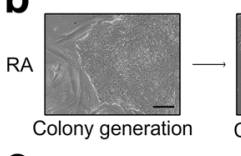

C
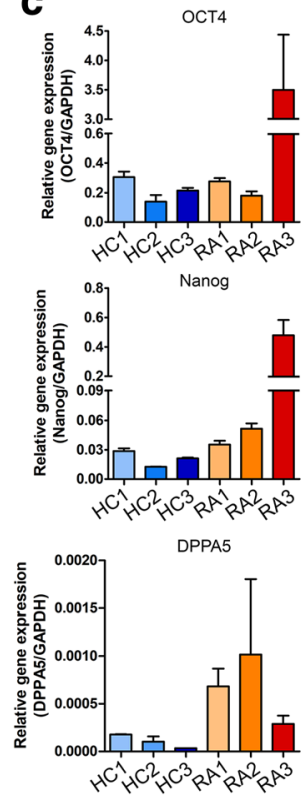

f
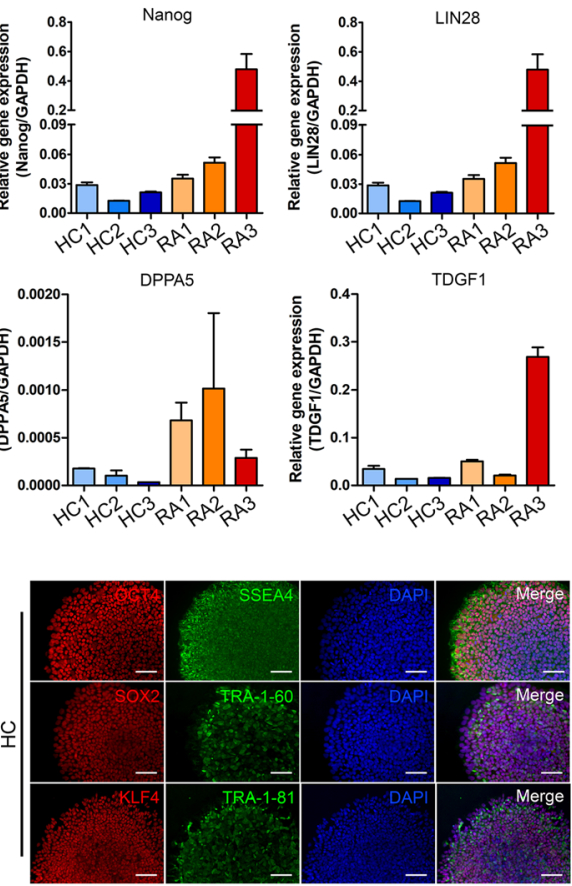

d

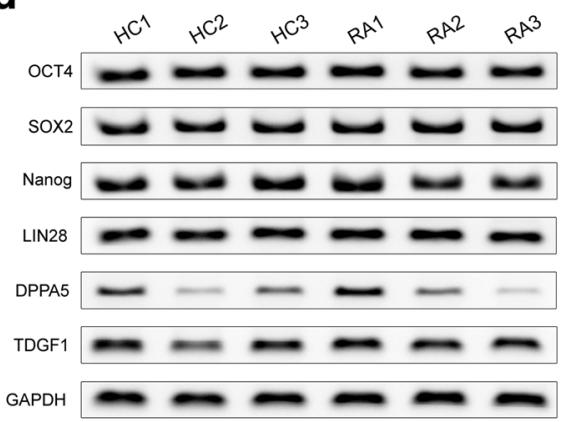

e
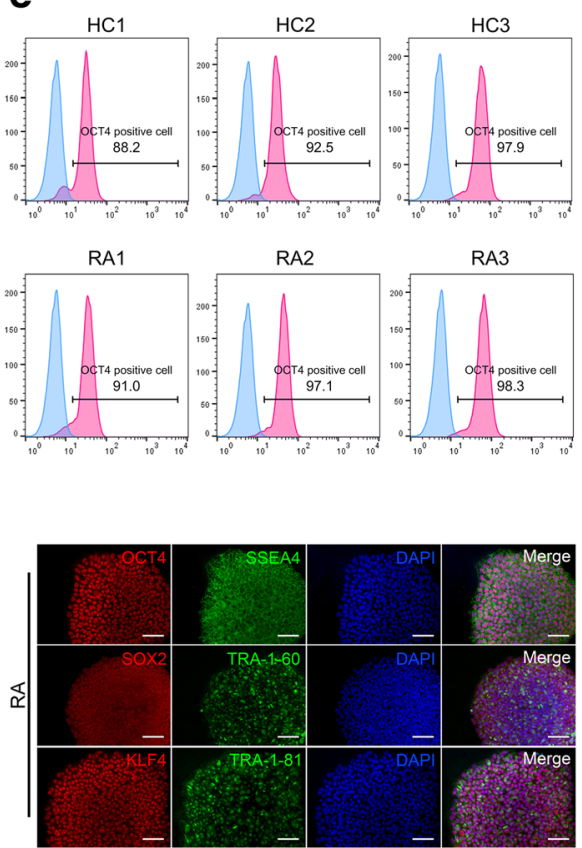

Fig. 1 Generation of iPSCs from healthy control subjects and RA patients with MTX-induced hepatotoxicity. a Scheme of generation of iPSCS from healthy controls and RA patients with MTX-induced hepatotoxicity. b Induction of iPSCs derived from RA patients with hepatotoxicity. $\mathbf{c}$ Real-time PCR data for pluripotency gene expression in IPSCs. d RT-PCR data for pluripotency gene expression in iPSCs. e Flow cytometry data of iPSCs showing a population of OCT3/4-positive cells. $\mathbf{f}$ Immunocytochemistry images showing that pluripotent markers (SSEA4, OCT3/4, TRA-1-60, Sox 2, TRA-1-81, and Klf4) were expressed in iPSCs from healthy control (HC)- and RA patient (RA)-iPSCs. Scale bars, $200 \mu \mathrm{m}$

are undifferentiated cells, did not express well, but the markers were significantly increased in hepatocyte-like cells (Fig. 2k). UGT1A1, UGT2B15, OATP1B1, OATP1B3, NTCP, MRP2, and MDR1 genes belonging to phases II and III, drug transporter gene, also significantly increased in hepatocyte-like cells compared with
iPSCs (Fig. 2l-m). The expression of AHR, FXR, GR, $P P A R \alpha, R X R A$, and SHP genes, the nuclear receptors that regulate the activity of CYP 450 enzyme, was also increased in hepatocyte-like cells (Fig. 2n). Together, these findings demonstrate that iPSCs could be differentiated through endoderm and hepatoblast states into 
Table 2 ALT and AST levels and MTHFR mutation analysis in RA patients

\begin{tabular}{|c|c|c|c|c|c|c|c|}
\hline Patient & Gender & Hepatotoxicity & MTX treatment & AST (IU/L) & ALT (IU/L) & $\begin{array}{l}\text { MTHFR mutation } \\
\text { C677T }\end{array}$ & $\begin{array}{l}\text { MTHFR mutation } \\
\text { A1298C }\end{array}$ \\
\hline $\mathrm{HCl}$ & Male & No & No & NA & NA & Hetero $(\mathrm{C} / \mathrm{T})$ & Hetero $(\mathrm{A} / \mathrm{C})$ \\
\hline $\mathrm{HC2}$ & Female & No & No & NA & NA & Wild (C/C) & Hetero (A/C) \\
\hline $\mathrm{HC} 3$ & Female & No & No & NA & NA & NA & NA \\
\hline RA1 & Female & Yes & $15 \mathrm{mg} /$ week & 170 & 220 & Homo $(T / T)$ & Wild (A/A) \\
\hline RA2 & Male & Yes & 7.5-15 mg/week & 57 & 131 & Wild (C/C) & Wild (A/A) \\
\hline RA3 & Male & Yes & 7.5-10 mg/week & 63 & 122 & Hetero $(\mathrm{C} / \mathrm{T})$ & Hetero (A/C) \\
\hline
\end{tabular}

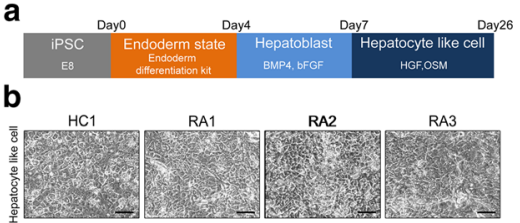

C

d
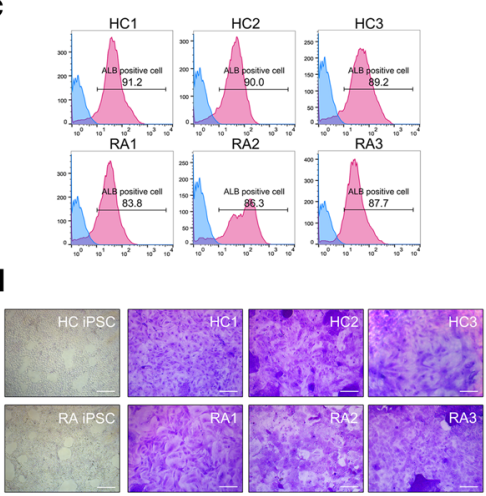

i iPSC marker

$\mathbf{K}_{\text {Phase I }}$

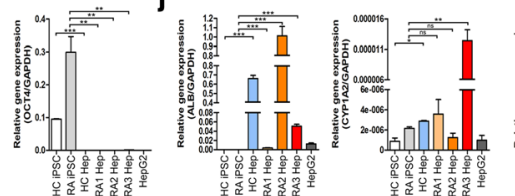

I Phase II
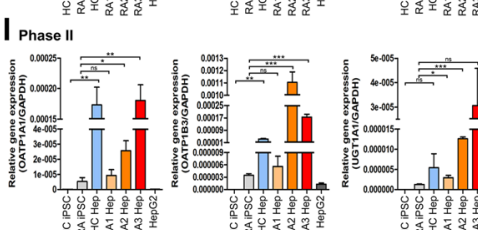
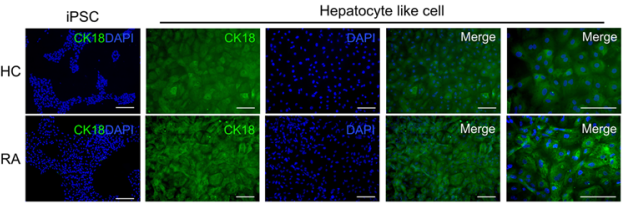

f
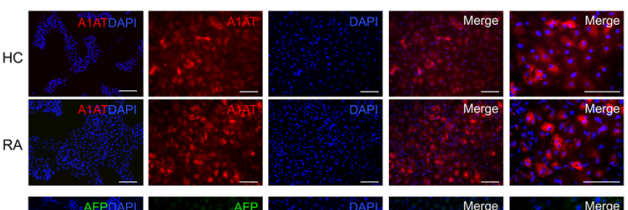

g
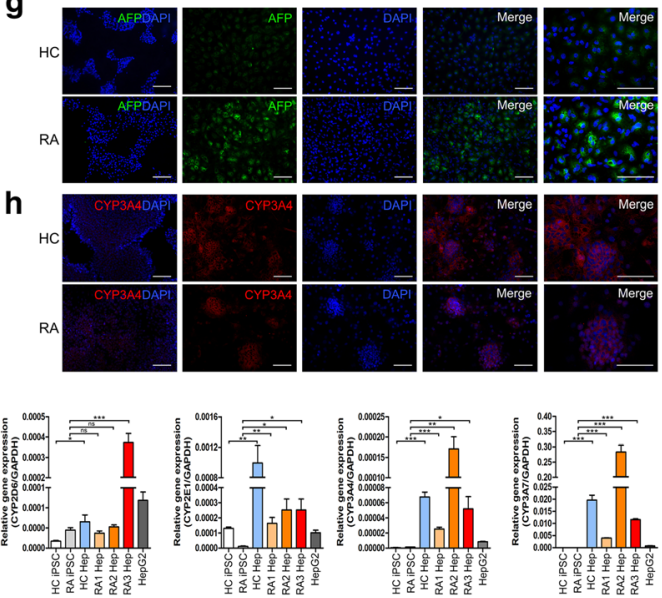

m Phase III
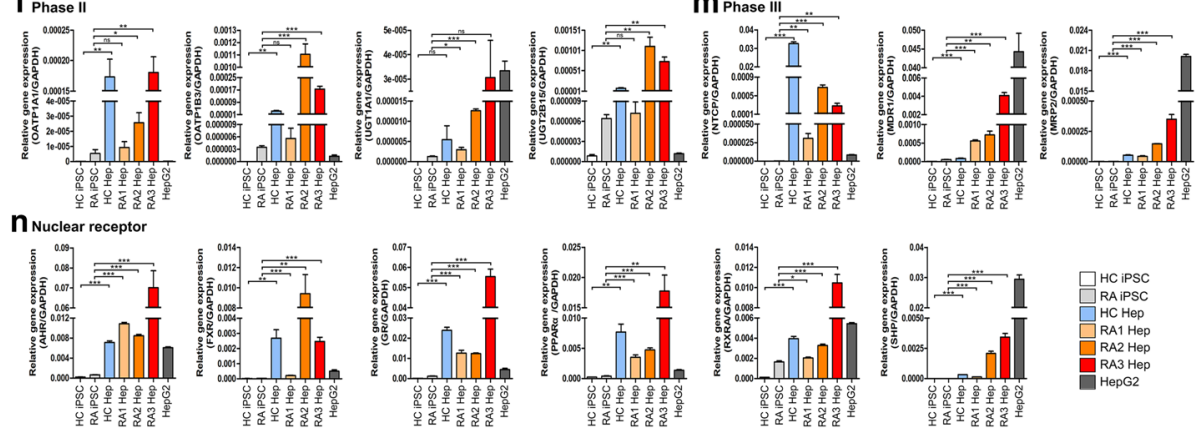

Fig. 2 Differentiation of iPSCs derived from RA patients with MTX-induced hepatotoxicity into hepatocyte-like cells. a Scheme of differentiation of iPSCs from healthy control and RA patients with MTX-induced hepatotoxicity using 2D monolayer culture. b Microscope images showing the morphology of hepatocyte-like cells differentiated over the course of 26 days. c Flow cytometry data of hepatocyte-like cells showing a population of albumin-positive cells. $\mathbf{d}$ Microscope image of periodic acid staining for detection of glycogen storage in differentiated hepatocyte-like cells. $\mathbf{e}-\mathbf{h}$ Immunocytochemistry of the indicated hepatocyte markers (CK18, A1AT, AFP, and CYP3A4). i-n Real-time PCR data for OCT4, albumin, phases I, II, and III and nuclear receptors that are related with hepatocyte function. Scale bars, $200 \mu \mathrm{m}$ 
hepatocyte-like cells with hepatocyte function and expression of hepatocyte markers by the $2 \mathrm{D}$ monolayer method.

\section{Recapitulation of MTX hepatotoxicity using 2D-cultured iPSC-derived hepatocytes}

To examine MTX toxicity using hepatocyte-like cells differentiated by the 2D monolayer method, hepatoblasts were re-seeded on day 8 of differentiation in 96-well plates ( $n=3$ for healthy controls, $n=3$ for RA patients) (Fig. 3a). Differentiation of hepatocyte-like cells was carried out in HBM with HGF and OSM until day 26. MTX was administered for 6 days, from day 21 to day 26. MTX was added at doses of $0 \mathrm{nM}, 1 \mathrm{nM}, 10 \mathrm{nM}, 100$
$\mathrm{nM}, 1 \mu \mathrm{M}, 10 \mu \mathrm{M}$, or $100 \mu \mathrm{M}$, and hepatotoxicity was confirmed by CCK- 8 assay. In RA patients, cell viability was decreased from $100 \%$ at $0 \mathrm{nM}$ MTX to $60 \%$ at $100 \mu \mathrm{M}$. By contrast, healthy controls were resistant to MTX-induced toxicity, and maintained viability above $80 \%$ at $100 \mu \mathrm{M}$ MTX (Fig. 3b). In cells derived from RA patients with hepatotoxicity, cell viability decreased significantly in $100 \mathrm{nM}(p<0.01$ vs. $0 \mathrm{nM}), 1 \mu \mathrm{M}(p<0.01)$, $10 \mu \mathrm{M}(p<0.001)$, and $100 \mu \mathrm{M}(p<0.01)$ MTX relative to $0 \mathrm{nM}$. ALT level in culture supernatant on day 26 was significantly higher at $100 \mathrm{nM}$ in cells derived from RA patient (Fig. 3c). These results suggested that hepatocyte-like cells derived from iPSCs of RA patients with MTX-induced toxicity are more sensitive to 100

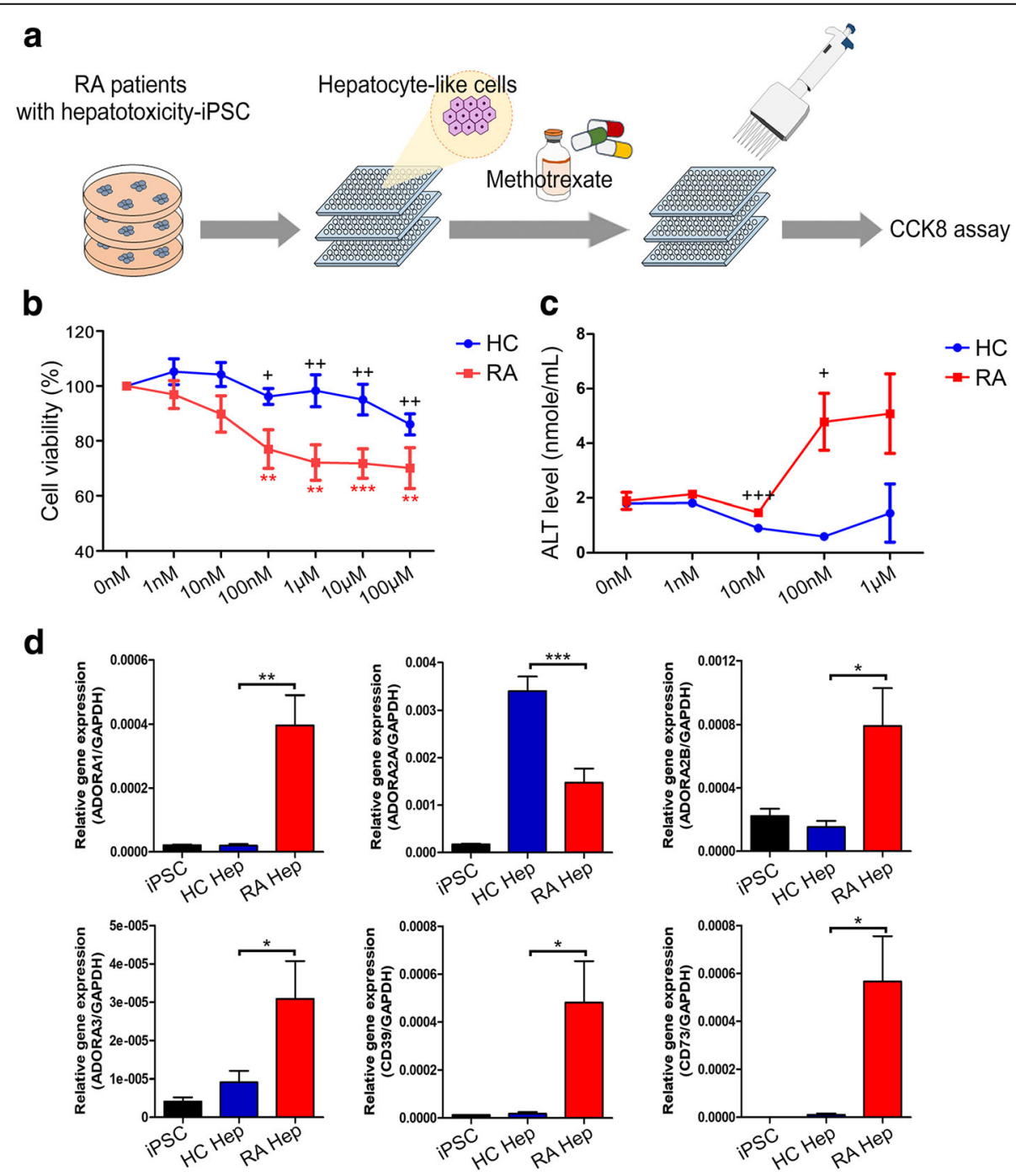

Fig. 3 Hepatotoxicity assay of hepatocyte-like cells derived from iPSCs from RA patients with hepatotoxicity. a Scheme of cytotoxicity assay using hepatocyte-like cells treated with MTX for 6 days. b CCK-8 assay data of hepatocyte-like cells derived from iPSCs from healthy controls and RA patients with hepatotoxicity. HC: healthy control group $(n=3)$, blue line; RA: RA patient group $(n=3)$, red line. c ALT level of hepatocyte-like cells derived from iPSCs from healthy control and RA patient with hepatotoxicity. $\mathbf{d}$ Real-time PCR data for ADORA receptors, CD39 and CD73 gene expression in hepatocyte-like cells and iPSCs. Statistical significance is expressed as $p$ value (Student's $t$ test) vs. 0 nM: ${ }^{*} p<0.05 ;{ }^{* *} p<0.01 ;{ }^{* * *} p<0.001$. Statistical significance is also expressed as $p$ value (Student's $t$ test) comparing HC and RA at each concentration: $+p<0.05 ;++p<0.01 ;+++p<0.001$ 
nM MTX and that iPSC-derived hepatocyte-like cells from healthy controls and RA patient are suitable for simulating MTX toxicity.

Adenosine receptors A1, A2A, A2B, A3, CD39, and CD73 are known to be associated with MTX acceptance and hepatotoxicity [28-30]. Therefore, we examined the difference in gene expression of iPSC-derived hepatocytelike cells between healthy control and RA patient with hepatotoxicity by real-time PCR. In this study, ADORA1, ADORA2B, ADORA3, CD39, and CD73 expression were higher in RA patient group with hepatotoxicity than that of HC. In contrast, ADORA2A was expressed lower in the RA patient group with hepatotoxicity than that of $\mathrm{HC}$ (Fig. 3d).

\section{Recapitulation of MTX-induced hepatotoxicity in 3D hepatocyte spheroids}

When MTX was administered for 6 days in 2D culture, cell viability differed between hepatocyte-like cells from healthy controls and hepatotoxic patients, but cell viability did not decrease below $50 \%$. To decrease viability of MTX-treated cells below 50\% and investigate the effect of long-term treatment with MTX, we tried to treat cells with MTX for more than 6 days. In the 2D-cultured state, apoptosis started to occur 30 days after hepatocyte differentiation. Hence, we decided to increase the survival period of hepatocytes by growing them in 3D spheroid culture. The hepatocyte spheroids were generated using the hanging drop system; we found that cell viability could be sustained for more than 40 days after differentiation when Matrigel matrix was present in the medium at a 1:100 ratio (Additional file 3). After hepatoblasts were mixed with basic Matrigel by centrifugation, the spheroids formed 3 days (healthy controls) or 7 days (RA patients) after aggregation (Fig. 4a, b). When hepatocyte spheroids were attached to the bottom of the dish after spheroid differentiation, the morphology of cells growing out from the spheroid was similar to that of primary hepatocytes [26] (Fig. 4a). IFA revealed that hepatocyte spheroids from both groups robustly expressed the hepatocyte markers albumin and A1AT (Fig. 4c). The fluorescence quantity per area of the spheroid is calculated and shown in a bar graph (Fig. 4d). As a result, the expression levels of albumin and A1AT were lower in RA hepatocyte-like cell spheroids compared to that of $\mathrm{HC}$.

Starting on day 15 after hepatoblast aggregation, we administered MTX to 3D hepatocyte spheroids at a dose of 0 to $100 \mu \mathrm{M}$. Two weeks later, we performed ATP assays to measure cell viability. In the healthy control group, ATP level (RFU) increased up to a MTX concentration of $10 \mathrm{nM}$, and then gradually decreased from 1 to $100 \mu \mathrm{M}$. By contrast, in the RA patient group, the ATP level in the spheroids was higher after treatment with $10 \mathrm{nM}$ MTX than after treatment with vehicle, and decreased significantly from $100 \mathrm{nM}$ to $100 \mu \mathrm{M}$ (Fig. 4e). Overall, the RA patient group had higher RFU values than the healthy control group. For determination of relative cell viability, the RFU value in vehicle was defined as $100 \%$ (Fig. 4f). Cell viability was below $50 \%$ at $1 \mu \mathrm{M}$ MTX in the RA patient group, and at doses above $10 \mu \mathrm{M}$ in the healthy patient group. Live/dead cell staining revealed that viability decreased relative to $0 \mathrm{nM}$ MTX at doses above $100 \mathrm{nM}$ (Fig. 4g).

To investigate drug-induced mitochondrial dysfunction, we stained with Mitotracker. The intensity of staining decreased in a MTX concentration-dependent manner in spheroids from the RA patient group (Fig. 4h), and the size of spheroids decreased at 10 and $100 \mu \mathrm{M}$ MTX. The shapes of the RA patient spheroids were abnormal, and Hoechst staining revealed damage to the nucleus, at doses above $100 \mathrm{nM}$. No evidence of nuclear damage could be observed in the healthy control spheroids.

In summary, we successfully generated 3D hepatocyte spheroids from iPSCs that were suitable for long-term treatment with MTX. Hepatocyte spheroids derived from RA patients were more sensitive to 14-day MTX treatment than those obtained from healthy control cells. Moreover, mitochondrial and nuclear staining revealed abnormalities in the respective subcellular compartments in iPSC-derived hepatocyte spheroids from RA patients.

\section{Discussion}

In this study, we generated 2D and 3D cultures of hepatocyte-like cells using iPSCs, and used these cultures to evaluate the hepatotoxicity of MTX. For cell differentiation, we used the Takebe protocol to differentiate iPSCs into hepatocyte-like cells via the endoderm and hepatoblast states [25]. In 2D culture, hepatocyte markers such as albumin, A1AT, and CK18 were expressed, and the differentiated hepatocyte-like cells had glycogen storage function and expressed drug metabolism genes such as phases I, II, and III. In addition, we could obtain hepatocyte-like cells from iPSCs derived from patients with hepatotoxicity following MTX administration, which could differentiate into albumin-positive hepatocyte-like cells at a yield of more than $80 \%$. These cells could be used as a platform to test for drug toxicity. Remarkably, we were able to perform long-term treatment with MTX in iPSC-derived 3D hepatocyte spheroid cultures, whereas the short cellular lifespans limited the MTX treatment period to 6 days in 2D culture. In iPSC-derived 3D hepatocyte spheroids, cell viability was maintained for more than 40 days after the start of hepatoblast aggregation, allowing us to evaluate hepatotoxicity over long-term (14-day) treatment periods. 

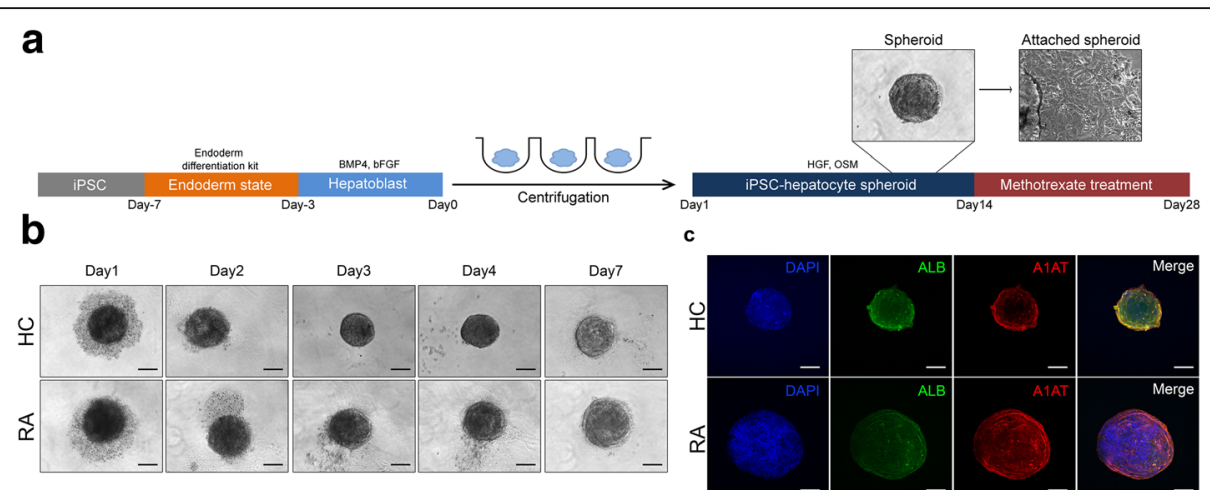

c

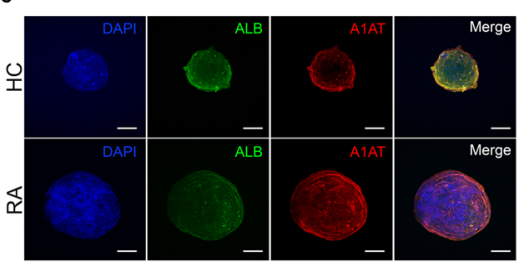

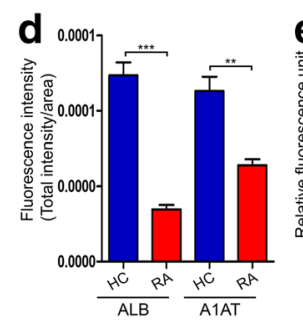

g

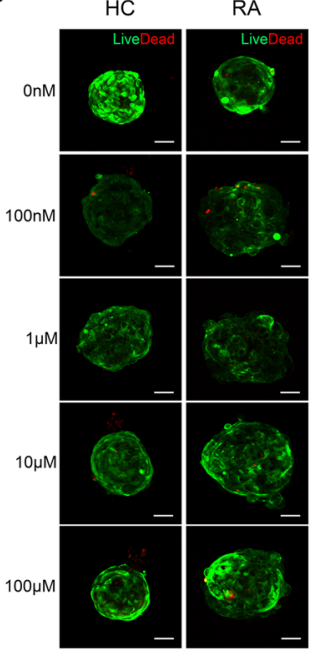

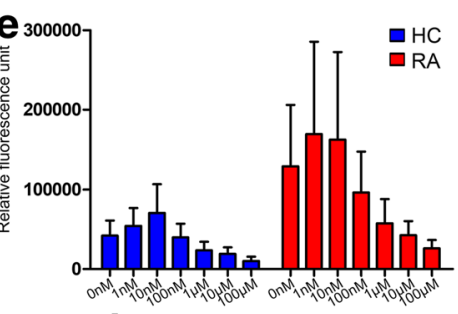

h
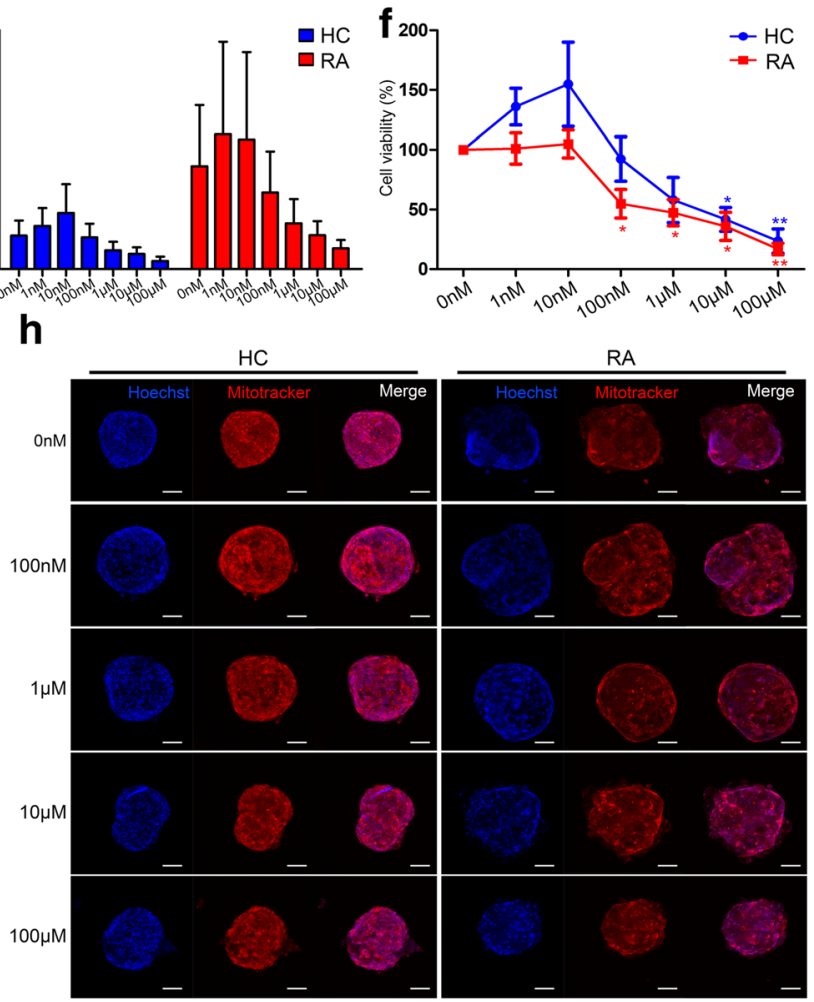

Fig. 4 Generation and hepatotoxicity assay of hepatocyte spheroids from iPSCs derived from RA patients. a Scheme of generation of 3D hepatocyte spheroids and morphology of attached spheroids. b Morphology of hepatocyte spheroids generated from HC- and RA-iPSCs. c z-stack confocal microscope image of hepatocyte spheroids expressing albumin and A1AT. $\mathbf{d}$ The fluorescence quantity per area of the spheroid calculated by image J program. e 3D spheroid cell viability. HC: healthy control group ( $n=3)$, blue bar; RA: RA patient group ( $n=3)$, red bar. $\mathbf{f}$ Cell viability data relative to vehicle (MTX, $0 \mathrm{nM})$. HC: healthy control group $(n=3)$, blue line; RA: RA patient group $(n=3)$, red line. Statistical significance is expressed as $p$ value (Student's $t$ test) vs. 0 nM: ${ }^{*} p<0.05 ;{ }^{* *} p<0.01 ;{ }^{* * *} p<0.001$. g Live/dead cell staining. Each image was obtained from a confocal z-stack. h Mitotracker and Hoechst staining, obtained from confocal z-stacks

Recently, 3D culture methods for mimicking the in vivo environment, along with monolayer cultures, have been actively studied as a method for hepatocyte culture, with the ultimate goal of testing drug hepatotoxicity and verifying drug effectiveness. For example, in a 3D bioprinting system in which HepG2 hepatocarcinoma cells are cultured on an alginate scaffold, hepatocyte markers were robustly expressed, and scaffold-free microspheres of primary hepatocytes increased cellular lifespan and albumin secretion [31-34]. However, these studies were also limited by the difficulty of securing sufficient numbers of primary hepatocytes for drug testing. In addition, when iPSCs are differentiated into scaffold-free microspheres, the metabolic environment of hepatocytes is maintained more effectively in 3D culture than 2D culture. Patient characteristics about hepatotoxicity were not reflected in this case as well; however, our results verified that hepatocyte-like cells derived from iPSCs from healthy and RA patients with MTX-induced hepatotoxicity showed different sensitivity against drugs. In 
particular, it was possible to simulate the hepatotoxicity of long-term drug treatment by administering MTX to iPSC-derived 3D hepatocyte cultures for 14 days.

In this study, we generated hepatocyte-like cells from iPSCs to test the toxicity of MTX, which is already known to be hepatotoxic. In previous studies, iPSCs were generated from patients with hepatotoxicity due to pazopanib, for use as a disease model, and iPSCs derived from patients with A1AT mutations were differentiated into hepatocyte-like cells [35-38]. For differentiation into iPSCs, we used PBMCs or skin fibroblasts of RA patients, in which the levels of ALT and AST rose from 57 to $170 \mathrm{IU} / \mathrm{L}$ and 122 to $220 \mathrm{IU} / \mathrm{L}$, respectively, after MTX administration. Mutant analyses of MTHFR [39], the candidate gene responsible for toxicity of MTX, revealed that the wild type, heterozygous mutants, and homozygous mutants were present in the patient group.

Pluripotent markers were expressed following iPSC differentiation: specifically, the genes encoding OCT3/4 and NANOG were expressed in cells derived from RA patients and healthy controls. iPSCs differentiated into hepatocyte-like cells that were more than $80 \%$ of which were albumin-positive (90.1\% in healthy controls; $85.9 \%$ in RA patients) and expressed the hepatocyte markers A1AT and CK18. Therefore, iPSCs are a suitable source of material for evaluating a drug's hepatotoxicity or efficacy. When cells were differentiated using the monolayer method, hepatocyte markers were expressed starting on day 18 , so we administered MTX during maturation until day 26; this regimen was based on a consideration of lifespan limitations in 2D culture. Thus, 2D hepatocyte-like cells are a good model for verifying the hepatotoxicity and efficacy of drugs over a short period of time.

RA is a systemic autoimmune disease associated with bone destruction and inflammation. When used as a first-line drug, DMARDs run the risk of drug-induced liver injury, which in some patients is more dangerous than the disease. Several mechanisms have been proposed for MTX-induced liver injury, but the exact cause remains to be elucidated. Previous studies reported mutations in the DHFR and MTHFR enzymes [3, 5, 40]. Yet, it is not possible to predict hepatotoxicity using these mutations because they are not applicable in some cases. As for the revealed mechanism of MTX, MTX enters the cell by reduced folate carrier 1 reduce folate receptor (RFC-1; SLC19A1), is changed to methotrexate polyglutamates (MTXglu), and suppresses the intracellular 5-aminoimidazole4-carboxamide ribonucleotide (AICAR) transformylase. This leads to upregulation of intracellular AICAR, which leads to an increase in adenosine $[29,30]$. Adenosine excreted in the extracellular fluid is known to bind to adenosine receptors A1, A2a with high affinity and A2b, and A3 with low affinity. In addition, ATP, ADP, and AMP are hydrolysis by CD39 and CD73 and increase adenosine. In particular, adenosine receptors $\mathrm{A} 2 \mathrm{a}$ and $\mathrm{A} 3$ receptors are known to affect the anti-inflammatory effect and immunosuppression in the intracellular space $[29,30]$. In a previous study, $A B C C 1$, SLC19A1, ADORA2A, and ADORA2B were found to be upregulated in RA patient' synovium that received MTX [29]. Another study has shown that the increase of adenosine by stimulation of A2B causes hepatic fibrosis [28]. In this study, ADOR A1, ADORA2B, CD39, and CD73 in iPSC-derived hepatocytes were expressed higher than $\mathrm{HC}$ in RA patient group with hepatotoxicity. In contrast, ADORA2A was expressed lower than $\mathrm{HC}$ in the RA patient group with hepatotoxicity. In addition, the expression of MDR1 (ABCB1) in the ATP binding cassette (ABC) transporter responsible for the release of MTX-Glu in the cells was more expressed in RA. As a result, the expression of ADORA1, ADORA2B, CD39, CD73 and MDR1 which are associated with adenosine binding was increased in RA hepatocyte-like cells, which might indicate more sensitivity to MTX. ADORA2A, which affects the anti-inflammatory effect, was decreased and ADORA2B, which may affect hepatic fibrosis, was increased in RA hepatocyte-like cells. These results suggest that the gene expression changes in RA hepatocyte-like cells may affect the outcomes related to hepatotoxicity.

In studies using Hep3B hepatocellular carcinoma cells, toxicity was observed at $100 \mathrm{nM}$ MTX [41]. In another study using another HepG2, toxicity was $43.7 \%$ when treated with $100 \mu \mathrm{M}$ MTX for $24 \mathrm{~h}$ and $17.69 \%$ when treated for $48 \mathrm{~h}$ [42]. Hepatocyte spheroids were prepared by mixing THP-1 and hTERT-HSC cells in HepaRG in a hanging drop system; cell viability was below $50 \%$ in $30 \mu \mathrm{M}$ MTX after a 14-day treatment [43]. In other cases, primary hepatocyte was used to bio-print liver tissue with endotherial cells and hepatic stellate cells; when MTX was treated at 100 and $1 \mu \mathrm{M}$ for 11 days and 14 days, LDH increased two to three times compared to vehicle and the results of the staining showed mild damage at $100 \mathrm{nM}$ and fibrosis at $1 \mu \mathrm{M}$ [44]. As far as we know, however, no previous study has examined MTX hepatotoxicity using patient-specific hepatocytes derived from iPSCs.

In this study, we generated hepatocyte-like cells using iPSCs, which can self-renew and provide patient-specific information. We found that the viability of hepatocytelike cells from RA patients with hepatotoxicity was reduced when MTX was administered at doses from 100 $\mathrm{nM}$ to $100 \mu \mathrm{M}$ for 6 days in $2 \mathrm{D}$ monolayer culture. When iPSC-derived 3D hepatocytes were treated with MTX for 14 days, viability of spheroids from RA patients decreased to $54.9 \%$ at $100 \mathrm{nM}, 47.4 \%$ at $1 \mu \mathrm{M}$, and $16.7 \%$ at $100 \mu \mathrm{M}$. On the other hand, spheroids from healthy controls were comparatively resistant, with viability of 
$92.3 \%$ at $100 \mathrm{nM}, 41.7 \%$ at $10 \mu \mathrm{M}$, and $23.5 \%$ at $100 \mu \mathrm{M}$. In the previous study, the toxicity of the carcinoma cell lines HepG2 and Hep3B was shown to be shorter in the treatment period of MTX than in the primary hepatocyte and iPSC-derived hepatocyte in this study. In contrast, the toxicity of MTX in liver tissue using primary hepatocytes, endothelial cells, and hepatic stellate cells in a previous study was similar to the period of MTX treatment and concentration with toxicity in this study. These results suggest that the toxicity study of this study system is similar to the toxicity seen in primary hepatocytes and reflects the sensitivity difference between healthy control and RA patients.

Mitochondrial dysfunction is a major mechanism underlying liver injury $[45,46]$. In this study, the distribution of staining in RA patients with hepatotoxicity was abnormal, suggesting that RA patients with hepatotoxicity are more susceptible to mitochondrial dysfunction than healthy controls.

3D hepatocyte spheroids can be generated by the hanging drop method, in 96-well round-bottom plates, or by bioprinting [47]. In this study, cells were aggregated by centrifugation in 96-well round-bottom plates. Although iPSC-derived hepatocyte spheroids can be formed efficiently by the hanging drop method, we used a system in which one spheroid was present in each well, to allow treatment with a series of drug concentrations, and added Matrigel to the medium to form extracellular matrix and thereby maintain cell viability. Thus, the platform developed in this study can be used for a variety of assays of drug toxicity at a series of MTX concentrations.

\section{Conclusion}

The toxicity of MTX was evaluated using iPSC-derived 2D hepatocyte-like cells and 3D hepatocyte spheroids. The results revealed that cultures derived from RA patients were more sensitive to MTX-induced hepatotoxicity than cultures derived from healthy control subjects. Because this system can be used to test hepatotoxicity for both short and long periods, it could be adapted into a test platform that could be monitored periodically. In addition, our findings provide evidence that patient-derived iPSCs could be used to study the mechanism of disease-related hepatotoxicity.

\section{Additional files}

Additional file 1: Immunochemisty and AP staining of iPSCs. $a, b$ Immunocytochemistry of HC- and RA-iPSCS. HC: healthy control; RA: RA patient with MTX-induced hepatotoxicity. c, d iPSCs generated from healthy controls and RA patients were positive for alkaline phosphatase staining. (JPG $21730 \mathrm{~kb}$ )

Additional file 2: Generation of iPSC-derived hepatocyte-like cells. a, b Morphology and immunocytochemistry images of iPSCs, endoderm, and hepatoblasts. On day 5, the endoderm marker SOX17 was expressed and pluripotency marker OCT3/4 was decreased. On day 8, the hepatoblast marker HNF4a was expressed and pluripotency marker OCT3/4 was decreased. Scale bars, 200 m. (JPG 11851 kb)

Additional file 3: Generation of iPSC-derived hepatocyte spheroids using the hanging drop method, and survival period. a Scheme for generation of iPSC-derived hepatocyte spheroids. b Morphology of iPSCderived hepatocyte spheroids during culture. Addition of Matrigel matrix (1:100 ratio in $25 \mu \mathrm{L}$ of medium) increased spheroid survival rate. $\mathrm{c}$ Immunocytochemistry of iPSC-derived hepatocyte spheroids. Albumin and A1AT marker were expressed. Scale bars, 200 m. (JPG 4520 kb)

\section{Abbreviations}

A1AT: Alpha-1 antitrypsin; ADORA1: Adenosine A1 receptor; ADORA2A: Adenosine A2A receptor; ADORA2B: Adenosine A2B receptor; ADORA3: Adenosine A3 receptor; ALB: Albumin; bFGF: Basic fibroblast growth factor; BMP4: Bone morphogenetic protein 4; CK18: Cytokeratin 18; CYP3A4: Cytochrome P450 3A4; DMARDs: Disease-modifying antirheumatic drugs; HC: Healthy control; HGF: Hepatocyte growth factor; iPSC: Humaninduced pluripotent stem cell; MTX: Methotrexate; NSAIDs: Nonsteroidal antiinflammatory drugs; OSM: Oncostatin M; PBMC: Peripheral blood mononuclear cell; RA: Rheumatoid arthritis

\section{Acknowledgements}

Not applicable.

\section{Funding}

This research was supported by a grant of the Korea Health Technology R\&D Project through the Korea Health Industry Development Institute (KHIDI), funded by the Ministry of Health \& Welfare, Republic of Korea (H18C1178, HI15(1062)

\section{Availability of data and materials}

All data pertaining to this manuscript are included within the article.

\section{Authors' contributions}

JK designed and performed the experiments, analyzed the results, and wrote the manuscript. YK performed data analysis and the experiments. JC carried out experiments and data analysis. HJ performed data analysis. $\mathrm{KL}$ performed the experiments. JK performed the experiments. NP performed statistical analysis. YAR performed data analysis. YN performed data analysis. JHJ helped analyze the results. All authors read and approved the final draft of the manuscript.

\section{Ethics approval and consent to participate}

This study was approved by the IRB of the Catholic University of Korea (IRB Number: KC13TISI0775). Written informed consent was obtained from all participants involved in this study.

Consent for publication

Not applicable.

\section{Competing interests}

The authors declare that they have no competing interests.

\section{Publisher's Note}

Springer Nature remains neutral with regard to jurisdictional claims in published maps and institutional affiliations.

\section{Author details}

${ }^{1}$ CISTEM laboratory, Convergent Research Consortium for Immunologic Disease, Seoul St. Mary's Hospital, College of Medicine, The Catholic University of Korea, Seoul 137-701, Republic of Korea. ${ }^{2}$ Division of Rheumatology, Department of Internal Medicine, Seoul St. Mary's Hospital, Institute of Medical Science, College of Medicine, The Catholic University of Korea, \#505, Banpo-Dong, Seocho-Gu, Seoul 137-701, Republic of Korea. ${ }^{3}$ Department of Biomedicine \& Health Sciences, Seoul St. Mary's Hospital, College of Medicine, The Catholic University of Korea, Seoul 137-701, Republic of Korea. 
Received: 20 September 2018 Revised: 20 November 2018 Accepted: 3 December 2018 Published online: 29 December 2018

\section{References}

1. Vaddi K, Luchi M. JAK inhibition for the treatment of rheumatoid arthritis: a new era in oral DMARD therapy. Expert Opin Investig Drugs. 2012:21:961-73.

2. Wessels JA, Huizinga TW, Guchelaar HJ. Recent insights in the pharmacological actions of methotrexate in the treatment of rheumatoid arthritis. Rheumatology (Oxford). 2008:47:249-55.

3. Tian $\mathrm{H}$, Cronstein BN. Understanding the mechanisms of action of methotrexate: implications for the treatment of rheumatoid arthritis. Bull NYU Hosp Jt Dis. 2007:65:168-73.

4. Sotoudehmanesh R, Anvari B, Akhlaghi M, Shahraeeni S, Kolahdoozan S. Methotrexate hepatotoxicity in patients with rheumatoid arthritis. Middle East J Dig Dis. 2010;2:104-9.

5. Aithal GP. Hepatotoxicity related to antirheumatic drugs. Nat Rev Rheumatol. 2011;7:139-50.

6. Soldatow VY, Lecluyse EL, Griffith LG, Rusyn I. In vitro models for liver toxicity testing. Toxicol Res (Camb). 2013;2:23-39.

7. Sjogren AK, Liljevald M, Glinghammar B, Sagemark J, Li XQ, Jonebring A, Cotgreave I, Brolen G, Andersson TB. Critical differences in toxicity mechanisms in induced pluripotent stem cell-derived hepatocytes, hepatic cell lines and primary hepatocytes. Arch Toxicol. 2014;88:1427-37.

8. Takahashi K, Yamanaka S. Induction of pluripotent stem cells from mouse embryonic and adult fibroblast cultures by defined factors. Cell. 2006:126: 663-76

9. Du Y, Wang J, Jia J, Song N, Xiang C, Xu J, Hou Z, Su X, Liu B, Jiang T, et al. Human hepatocytes with drug metabolic function induced from fibroblasts by lineage reprogramming. Cell Stem Cell. 2014;14:394-403.

10. Ma X, Duan Y, Tschudy-Seney B, Roll G, Behbahan IS, Ahuja TP, Tolstikov V, Wang C, McGee J, Khoobyari S, et al. Highly efficient differentiation of functional hepatocytes from human induced pluripotent stem cells. Stem Cells Transl Med. 2013;2:409-19.

11. Davidson MD, Ware BR, Khetani SR. Stem cell-derived liver cells for drug testing and disease modeling. Discov Med. 2015;19:349-58.

12. Schwartz RE, Trehan K, Andrus L, Sheahan TP, Ploss A, Duncan SA, Rice CM, Bhatia SN. Modeling hepatitis $C$ virus infection using human induced pluripotent stem cells. Proc Natl Acad Sci U S A. 2012;109:2544-8.

13. Shi $Y$, Inoue $H$, Wu JC, Yamanaka S. Induced pluripotent stem cell technology: a decade of progress. Nat Rev Drug Discov. 2017;16:115-30.

14. Grskovic M, Javaherian A, Strulovici B, Daley GQ. Induced pluripotent stem cells--opportunities for disease modelling and drug discovery. Nat Rev Drug Discov. 2011;10:915-29.

15. Anson BD, Kolaja KL, Kamp TJ. Opportunities for use of human iPS cells in predictive toxicology. Clin Pharmacol Ther. 2011;89:754-8.

16. Si-Tayeb K, Noto FK, Nagaoka M, Li J, Battle MA, Duris C, North PE, Dalton S, Duncan SA. Highly efficient generation of human hepatocyte-like cells from induced pluripotent stem cells. Hepatology. 2010;51:297-305.

17. Hannan NR, Segeritz CP, Touboul T, Vallier L. Production of hepatocyte-like cells from human pluripotent stem cells. Nat Protoc. 2013;8:430-7.

18. Chen YF, Tseng CY, Wang HW, Kuo HC, Yang WW, Lee OK. Rapid generation of mature hepatocyte-like cells from human induced pluripotent stem cells by an efficient three-step protocol. Hepatology. 2012;55:1193-203.

19. Szkolnicka D, Farnworth SL, Lucendo-Villarin B, Storck C, Zhou W, Iredale JP, Flint O, Hay DC. Accurate prediction of drug-induced liver injury using stem cell-derived populations. Stem Cells Transl Med. 2014;3:141-8.

20. Siller R, Greenhough S, Naumovska E, Sullivan GJ. Small-molecule-driven hepatocyte differentiation of human pluripotent stem cells. Stem Cell Reports. 2015;4:939-52.

21. Shan J, Schwartz RE, Ross NT, Logan DJ, Thomas D, Duncan SA, North TE, Goessling W, Carpenter AE, Bhatia SN. Identification of small molecules for human hepatocyte expansion and iPS differentiation. Nat Chem Biol. 2013:9: 514-20.

22. Gieseck RL 3rd, Hannan NR, Bort R, Hanley NA, Drake RA, Cameron GW, Wynn TA, Vallier L. Maturation of induced pluripotent stem cell derived hepatocytes by 3D-culture. PLoS One. 2014;9:e86372.

23. Levy G, Bomze D, Heinz S, Ramachandran SD, Noerenberg A, Cohen M, Shibolet O, Sklan E, Braspenning J, Nahmias Y. Long-term culture and expansion of primary human hepatocytes. Nat Biotechnol. 2015;33:1264.
24. Kim Y, Rim YA, Yi H, Park N, Park SH, Ju JH. The generation of human induced pluripotent stem cells from blood cells: an efficient protocol using serial plating of reprogrammed cells by centrifugation. Stem Cells Int. 2016; 2016:1329459.

25. Takebe T, Zhang RR, Koike H, Kimura M, Yoshizawa E, Enomura M, Koike N, Sekine $\mathrm{K}$, Taniguchi $\mathrm{H}$. Generation of a vascularized and functional human liver from an iPSC-derived organ bud transplant. Nat Protoc. 2014;9:396-409.

26. Bartlett DC, Hodson J, Bhogal RH, Youster J, Newsome PN. Combined use of $\mathrm{N}$-acetylcysteine and Liberase improves the viability and metabolic function of human hepatocytes isolated from human liver. Cytotherapy. 2014;16:800-9.

27. Huang P, Zhang L, Gao Y, He Z, Yao D, Wu Z, Cen J, Chen X, Liu C, Hu Y, et al. Direct reprogramming of human fibroblasts to functional and expandable hepatocytes. Cell Stem Cell. 2014;14:370-84.

28. Cronstein BN, Sitkovsky M. Adenosine and adenosine receptors in the pathogenesis and treatment of rheumatic diseases. Nat Rev Rheumatol. 2017:13:41-51.

29. Houlder EL, Millier MJ, Highton J, Gwynne-Jones D, Stamp LK, Hessian PA. Expression of the genes facilitating methotrexate action within subcutaneous rheumatoid nodules. Clin Exp Rheumatol. 2017;35:943-7.

30. Bath RK, Brar NK, Forouhar FA, Wu GY. A review of methotrexate-associated hepatotoxicity. J Dig Dis. 2014;15:517-24.

31. Fey SJ, Wrzesinski K. Determination of drug toxicity using 3D spheroids constructed from an immortal human hepatocyte cell line. Toxicol Sci. 2012; 127:403-11.

32. Jeon H, Kang K, Park SA, Kim WD, Paik SS, Lee SH, Jeong J, Choi D. Generation of multilayered 3D structures of HepG2 cells using a bio-printing technique. Gut Liver. 2017:11:121-8.

33. Meier F, Freyer N, Brzeszczynska J, Knospel F, Armstrong L, Lako M, Greuel S, Damm G, Ludwig-Schwellinger E, Deschl U, et al. Hepatic differentiation of human iPSCs in different 3D models: a comparative study. Int J Mol Med. 2017:40:1759-71.

34. Takai A, Fako V, Dang H, Forgues M, Yu Z, Budhu A, Wang XW. Threedimensional organotypic culture models of human hepatocellular carcinoma. Sci Rep. 2016;6:21174

35. Choudhury Y, Toh YC, Xing J, Qu Y, Poh J, Huan L, Tan HS, Kanesvaran R, Yu $\mathrm{H}$, Tan MH. Patient-specific hepatocyte-like cells derived from induced pluripotent stem cells model pazopanib-mediated hepatotoxicity. Sci Rep. 2017;7:41238.

36. Rashid ST, Corbineau S, Hannan N, Marciniak SJ, Miranda E, Alexander G, Huang-Doran I, Griffin J, Ahrlund-Richter L, Skepper J, et al. Modeling inherited metabolic disorders of the liver using human induced pluripotent stem cells. J Clin Invest. 2010;120:3127-36.

37. Griscelli F, Ezanno H, Soubeyrand M, Feraud O, Oudrhiri N, Bonnefond A, Turhan AG, Froguel P, Bennaceur-Griscelli A. Generation of an induced pluripotent stem cell (iPSC) line from a patient with maturity-onset diabetes of the young type 3 (MODY3) carrying a hepatocyte nuclear factor 1-alpha (HNF1A) mutation. Stem Cell Res. 2018;29:56-9.

38. Choi SM, Kim Y, Shim JS, Park JT, Wang RH, Leach SD, Liu JO, Deng C, Ye Z Jang $Y Y$. Efficient drug screening and gene correction for treating liver disease using patient-specific stem cells. Hepatology. 2013:57:2458-68.

39. Kluijtmans LA, Wendel U, Stevens EM, van den Heuvel LP, Trijbels FJ, Blom $\mathrm{HJ}$. Identification of four novel mutations in severe methylenetetrahydrofolate reductase deficiency. Eur J Hum Genet. 1998;6: 257-65.

40. Howard SC, McCormick J, Pui CH, Buddington RK, Harvey RD. Preventing and managing toxicities of high-dose methotrexate. Oncologist. 2016;21: 1471-82.

41. Yiang GT, Chou PL, Hung YT, Chen JN, Chang WJ, Yu YL, Wei CW. Vitamin C enhances anticancer activity in methotrexatetreated Hep3B hepatocellular carcinoma cells. Oncol Rep. 2014;32:1057-63.

42. Sadeghian I, Khalvati B, Ghasemi Y, Hemmati S. TAT-mediated intracellular delivery of carboxypeptidase $\mathrm{G} 2$ protects against methotrexate-induced cell death in HepG2 cells. Toxicol Appl Pharmacol. 2018:346:9-18.

43. Prestigiacomo V, Weston A, Messner S, Lampart F, Suter-Dick L. Pro-fibrotic compounds induce stellate cell activation, ECM-remodelling and Nrf2 activation in a human 3D-multicellular model of liver fibrosis. PLoS One. 2017:12:e0179995

44. Norona LM, Nguyen DG, Gerber DA, Presnell SC, LeCluyse EL. Editor's highlight: modeling compound-induced fibrogenesis in vitro using threedimensional bioprinted human liver tissues. Toxicol Sci. 2016;154:354-67. 
45. Begriche K, Massart J, Robin MA, Borgne-Sanchez A, Fromenty B. Drug-induced toxicity on mitochondria and lipid metabolism: mechanistic diversity and deleterious consequences for the liver. J Hepatol. 2011;54:773-94.

46. Russmann S, Kullak-Ublick GA, Grattagliano I. Current concepts of mechanisms in drug-induced hepatotoxicity. Curr Med Chem. 2009;16: 3041-53.

47. Sirenko O, Hancock MK, Hesley J, Hong D, Cohen A, Gentry J, Carlson CB, Mann DA. Phenotypic characterization of toxic compound effects on liver spheroids derived from iPSC using confocal imaging and three-dimensional image analysis. Assay Drug Dev Technol. 2016;14:381-94.

Ready to submit your research? Choose BMC and benefit from:

- fast, convenient online submission

- thorough peer review by experienced researchers in your field

- rapid publication on acceptance

- support for research data, including large and complex data types

- gold Open Access which fosters wider collaboration and increased citations

- maximum visibility for your research: over $100 \mathrm{M}$ website views per year

At $B M C$, research is always in progress.

Learn more biomedcentral.com/submissions 